\title{
Caracterização físico-química e biológica do caule de Caesalpinia ferrea Mart.
}

\author{
Frasson, A. P. Z. '; Bittencourt, C. F. ${ }^{2}$; Heinzmann, B. M. ${ }^{2 *}$ \\ ${ }^{1}$ Centro de Ciências da Saúde, UNIJUI, Campus Universitário, ljuí, RS; \\ ${ }^{2}$ Departamento de Farmácia Industrial, Universidade Federal de Santa Maria, \\ Campus Universitário, Santa Maria, RS.
}

\begin{abstract}
RESUMO: Visando estabelecer parâmetros para o controle da qualidade do caule de Caesalpinia ferrea Mart. (Caesalpiniaceae), foram realizados testes preconizados pela Farmacopéia Brasileira IV e pela Organização Mundial da Saúde para a avaliação da pureza, através das determinações de materiais estranhos, cinzas totais, cinzas insolúveis em ácido, umidade, ensaios-limites de cloretos e sulfatos, além da pesquisa de contaminantes microbianos no material pulverizado. Para a caracterização dos constituintes, eventualmente presentes na droga vegetal, foram realizadas as determinações de taninos, dos índices de espuma, intumescimento e amargor e o teste de hemólise; também foi realizada a caracterização do extrato etanólico bruto e suas frações por cromatografia em camada delgada.
\end{abstract}

Unitermos: Caesalpinia ferrea; controle de qualidade; drogas vegetais

ABSTRACT: Physico-chemical and biological characterization of Caesalpinia ferrea Mart. stems. In order to establish parameters for the control quality of Caesalpinia ferrea Mart. stem, the drug was characterized by the methods described in Farmacopéia Brasileira IV and by the World Health Organization. The powdered plant material was submitted to the following tests for purity evaluation: foreign matter, total ash, acid insoluble ash, water content, chloride and sulfate limit assays, and microbiological contamination. Determination of haemolytic activity, foaming index, swelling index and bitterness index were done to characterize the constituents eventually present in the drug, as well as the characterization of the ethanolic crude extract and its fractions by thinlayer chromatography.

Key words: Caesalpinia ferrea; control quality; plant drugs 


\section{INTRODUÇÃO}

Além da descoberta de constituintes naturais que sirvam como protótipos para o desenvolvimento de novos medicamentos, a pesquisa com as plantas medicinais nativas visa fornecer subsídios para a prática de uma fitoterapia racional, através do uso de medicamentos fitoterápicos de qualidade e com eficácia e segurança comprovadas. A OMS considera a fitoterapia nos seus programas e sugere procedimentos básicos para a validação de drogas vegetais uma vez que, devido à pobreza e falta de acesso à medicina moderna, 65 a $80 \%$ da população mundial, que vive em países em desenvolvimento, depende essencialmente de plantas medicinais para o tratamento das enfermidades (WHO, 1992; RATES, 2001a).

Apesar do número crescente de publicações relatando a análise fitoquímica e a avaliação da atividade farmacológica de espécies vegetais nativas, até o presente não existem estudos suficientes para a utilização racional da maioria das plantas medicinais brasileiras (RATES, 2001b). O fato de constarem apenas duas monografias de plantas nativas na Farmacopéia Brasileira IV (1988), entre as vinte monografias de drogas vegetais incluídas até o momento, confirma esta realidade.

Entre os estudos necessários para garantir a qualidade de uma droga vegetal encontramse os testes de autenticidade (caracterização organoléptica e identificação macroscópica e microscópica), testes de pureza e integridade (cinzas totais, cinzas insolúveis em ácido, umidade e determinação de materiais estranhos, contaminantes microbiológicos e metais pesados) e análises qualitativas e quantitativas dos constituintes ativos, quando conhecidos (BRASIL, 2000).

Caesalpinia ferrea Martius é uma árvore nativa do Brasil, empregada na medicina popular para o tratamento de afecções bronco-pulmonares e distúrbios gastrintestinais. Experimentos em animais indicaram atividades analgésica, antiinflamatória e antiúlcera para extratos dos frutos e caule da planta (BACCHI; SERTIÉ, 1991, 1994; CARVALHO et al., 1996). Recentemente, Frasson (2002) relatou a atividade antimicrobiana in vitro do extrato e de frações obtidas a partir de caules da planta.

Com o objetivo de determinar parâmetros para o controle de qualidade do caule de $C$. ferrea, planta medicinal nativa, considerando sua eventual inclusão na Farmacopéia Brasileira, foram realizados os testes para a caracterização físico-química e biológica da droga vegetal, segundo metodologias descritas pela Farmacopéia Brasileira (1988) e pela Organização Mundial da Saúde (WHO, 1992).

\section{MATERIAL E MÉTODOS}

\section{Material vegetal}

Caule de um exemplar de Caesalpinia ferrea Mart. ex. Tul. var. leiostachya Benth (Caesalpiniaceae); local e época de coleta: Campus da UFSM, Santa Maria, RS, maio de 1998; identificação e exsicata: Gilberto Dolejal Zanetti (DFI/UFSM), SMDB 8556 (Herbário UFSM); processamento: secagem em estufa de ar circulante $\left(40^{\circ} \mathrm{C}\right)$, pulverização em moinho de pás e tamisação (ANM = 0,86 $\mu \mathrm{m})$.

\section{Métodos}

As determinações de materiais estranhos, cinzas totais e cinzas insolúveis em ácido, bem como os ensaios limite para cloretos e sulfatos e a contagem de microrganismos viáveis e patógenos foram realizadas conforme preconizado pela Farmacopéia Brasileira (1988). Para a determinação dos índices de amargor, espuma e intumescimento e teste de hemólise foram realizadas as 
metodologias descritas pela Organização Mundial da Saúde (WHO, 1992); a determinação do teor de taninos foi feita segundo a metodologia descrita por Glasl (1983).

\section{Obtenção e fracionamento do extrato etanólico bruto}

O extrato etanólico bruto foi obtido através da extração em aparelho de Soxhlet e concentrado em evaporador rotatório, na temperatura de $40^{\circ} \mathrm{C}$, sendo conservado em dessecador até peso constante, para determinação do seu rendimento. $O$ fracionamento foi realizado por extração seqüencial com solventes de polaridade crescente (éter de petróleo, diclorometano, acetato de etila e n-butanol).

\section{Caracterização do extrato e suas frações por cromatografia em camada delgada}

Adsorvente: cromatofolhas de gel de sílica $\mathrm{G} 60 \mathrm{~F}_{254}$ (Merck); eluentes: clorofórmio:metanol (95:5) (frações acetato de etila e diclorometano); éter de petróleo:acetona (9:1) (frações éter de petróleo e diclorometano); acetato de etila:ácido fórmico:água (80:10:10) (frações butanólica e acetato de etila). Substâncias de referência: $\beta$-sitosterol, eucaliptol e ácido gálico. Desenvolvimento em câmara saturada, $12 \mathrm{~cm}$. Detecção: UV, $\mathrm{FeCl}_{3}$, anisaldeído- $\mathrm{H}_{2} \mathrm{SO}_{4}$, solução oxalo-bórica.

\section{RESULTADOS E DISCUSSÃO}

Não foram encontrados materiais estranhos ao vegetal, na amostra pesquisada, pelo fato do caule ter sido previamente selecionado e moído.

O teor obtido de cinzas insolúveis em ácido $(0,153 \%$ ou $1,53 \mathrm{mg} / \mathrm{Kg})$ indica que o material vegetal utilizado apresenta pequena quantidade de cinzas provenientes da contaminação ambiental. Teores de até $1 \%$ de cinzas insolúveis em ácido são aceitáveis, considerando vegetais que não sejam ricos em ácido silícico ou silicatos. $O$ caule de $C$. ferrea contém uma quantidade considerável de cinzas totais $(5,31 \%)$, o que pode ser explicado pela presença de sais inorgânicos no material vegetal (HÄNSEL et al., 1999).

O teor obtido de água e substâncias voláteis foi de 5,54\% e encontra-se abaixo dos limites gerais preconizados, que são de 8 a 14\% (FARMACOPÉIA BRASILEIRA, 1988; WHO, 1992; HÄNSEL et al., 1999; FARIAS, 2002). No entanto, devido à inexistência de uma monografia para C. ferrea que padronize o limite de umidade, não existem parâmetros comparativos na literatura.

O índice de amargor encontrado (1,68 unidades/g) permite concluir que a droga contém substâncias amargas, especialmente considerando a diluição do material vegetal empregado no ensaio, embora o caule de C. ferrea não seja "fortemente amargo".

O índice de intumescimento foi de $1,5 \mathrm{ml}$, o que sugere a presença de mucilagem e/ou goma no material vegetal analisado (FARMACOPÉIA BRASILEIRA, 1988; WHO, 1992; HÄNSEL et al., 1999).

A amostra apresentou menos do que 0,0003546 ppm de cloretos e menos do que 0,0012008 ppm de sulfatos, que correspondem às quantidades máximas permitidas para $1 \mathrm{~g}$ de amostra.

Não foram encontrados microrganismos considerados patogênicos na amostra, embora tenha sido verificada a presença de contaminantes microbianos, fato que é considerado normal, uma vez que os microrgansimos são onipresentes. Na contagem de microrganismos viáveis, em placas, foram obtidas quantidades inferiores a $10 \mathrm{UFC} / \mathrm{g}$ para bactérias e $8,03 \times 10^{2} \mathrm{UFC} / \mathrm{g}$ para fungos, sendo que os limites aceitáveis são $10^{5}$ e $10^{4} \mathrm{UFC} / \mathrm{g}$, respectivamente (WHO, 1992; HÄNSEL et al., 1999; FARIAS, 2002). 
Os resultados obtidos para o índice de espuma (IE<100) e teste de hemólise (negativo até a concentração de $5 \%$ do extrato), somados ao perfil cromatográfico do extrato etanólico bruto e de suas frações, indicam ausência de saponinas para o caule de $C$. ferrea e contradizem os resultados descritos até o momento (BACCHI; SERTIÉ, 1991 e 1994).

Na determinação de taninos, através da determinação de polifenóis totais (PT=0,0764\%) e polifenóis não-absorventes (PNA $=0,0556 \%$ ), foram obtidos baixos teores de taninos totais (TT=0,0208\%), enquanto que na literatura são citadas concentrações de até 9,2\% (BACCHI; SERTIÉ, 1994). Existem vários métodos descritos para a determinação de taninos, tendo-se optado neste trabalho por uma metodologia já validada cientificamente (GLASL, 1983).

A presença de taninos hidrolisáveis e seus monômeros em outras espécies de Caesalpinia foi descrita na literatura (WAGNER, 1993; NAKAMURA et al., 2002). Os baixos teores de taninos obtidos neste trabalho para o caule de $C$. ferrea estão de acordo com o observado na cromatografia em camada delgada, uma vez que as manchas visualizadas, após nebulização com cloreto férrico, sugeriram baixas concentrações deste grupo de constituintes. Manchas fluorescentes, sob luz UV e fluorescência intensa com solução oxalo-bórica, as quais apresentam cor amarela após nebulização com anisaldeído- $\mathrm{H}_{2} \mathrm{SO}_{4}$, com $\mathrm{R}_{\mathrm{f}}=0,36 ; 0,31 ; 0,20$ e 0,16, utilizando-se como eluente $\mathrm{CHCl}_{3}: \mathrm{MeOH}$ (95:5), indicam a presença de flavonóides na fração acetato de etila, em menor quantidade, na fração diclorometano. A presença de flavonóides em outras espécies de Caesalpinia foi descrita por vários autores (Mc PHERSON et al., 1983; CHE et al., 1986; NAMIKOSKI et al., 1987). As frações éter de petróleo e diclorometano foram cromatografadas com o eluente éter de petróleo:acetona (9:1), tendo como substâncias de referência o eucaliptol $\left(R_{f}=0,33\right)$ e o $\beta$-sitosterol $\left(R_{f}=0,21\right)$. Manchas de cor violácea, após nebulização com anisaldeído- $\mathrm{H}_{2} \mathrm{SO}_{4}$, de $\mathrm{R}_{\mathrm{f}}=0,77 ; 0,62$; 0,32; 0,22 e 0,16 sugerem a presença de terpenos nestas frações (STAHL; JORK, 1969).

Os testes realizados, visando fornecer subsídios para o desenvolvimento de metodologias de controle de qualidade para o caule de C. ferrea, foram feitos em triplicata. No entanto, o material utilizado nestes ensaios foi coletado de um único exemplar da espécie em estudo. Os resultados aqui descritos referentes aos teores de taninos e saponinas divergem daqueles encontrados na literatura para o caule de $C$. ferrea. Uma vez que o teor de constituintes vegetais varia conforme a raça química, a época de coleta, o clima, a constituição do solo e a idade da planta, entre outros fatores, são necessários estudos com um maior número de plantas, visando validar os resultados obtidos. Outro ponto crítico para a elaboração de uma monografia de $C$. ferrea é a falta de conhecimento sobre seus constituintes ativos, responsáveis pelas diferentes atividades farmacológicas comprovadas nos testes in vitro e pré-clínicos. Sem esta informação, não é possível desenvolver uma metodologia adequada para o doseamento da(s) substâncias(s) ativa(s). Uma das alternativas seria a escolha de um grupo de substâncias marcadoras, que possa servir de referência, como por exemplo, os flavonóides (HÄNSEL et al., 1999). Estudos científicos sistemáticos, utilizando metodologias padronizadas e validadas, são indispensáveis para a elaboração de uma monografia do caule de $C$. ferrea, a fim de estabelecer teores mínimos dos constituintes ativos presentes no farmacógeno, para que este apresente uma qualidade aceitável. Estudos com um maior número de plantas, de procedências diferentes, também irão possibilitar a obtenção de valores para os parâmetros físico-químicos que sejam representativos da espécie.

\section{AGRADECIMENTOS}

Ao botânico Gilberto Dolejal Zanetti pela localização e identificação do material vegetal. Apoio financeiro: CAPES. 


\section{REFERÊNCIAS BIBLIOGRÁFICAS}

BACCHI, E.; SERTIÉ, J. A. Identificação Cromatográfica e Ação Farmacológica de Extratos de Styrax camporum Pohl e Caesalpinia ferrea Martius. Revista Farmácia e Bioquímica da Universidade de São Paulo, v. 27, n. 2, p. 137-49, 1991.

BACCHI, E.; SERTIÉ, J. A. Antiulcer action of Styrax camporum and Caesalpinia ferrea in rats. Planta Medica. v. 60, n. 2, p. 118-20, 1994.

BRASIL. Ministério da Saúde. Agência Nacional de Vigilância Sanitária. Resolução de Diretoria Colegiada $(R D C) n^{\circ} 17$, de 24 de fevereiro de 2000. Aprova regulamento técnico, normatizando o registro de medicamentos fitoterápicos junto ao Sistema de Vigilância Sanitária. Diário Oficial da União, 2000.

CARVALHO, J. C. T.; TEIXEIRA, J. R. M.; SOUZA, P. J. C. et al. Preliminary studies of analgesic and antiinflammatory properties of Caesalpinia ferrea crude extract. Journal of Ethnopharmacology. v. 53, p. 175-8, 1996.

CHE, C.; McPHERSON, D.; CORDELL, G. A. et al. Pulcherralpin, a new diterpene ester from Caesalpinia pulcherrima. Journal of Natural Products, v. 49, n. 4, p. 561-9, 1986.

FARIAS, M. R. Avaliação da qualidade de matérias-primas vegetais. In: SIMÕES, C.M.O.; SCHENKEL, E.P.; GOSMANN, G.; MELLO, J.C.P.; MENTZ, L.A.; PETROVICK, P.R. (Org.). Farmacognosia: da planta ao medicamento. 4. ed. Porto Alegre: Editora da Universidade; Florianópolis: EdUFSC, p.199-222, 2002.

FARMACOPÉIA BRASILEIRA. 4. ed. Parte I. São Paulo : Atheneu, 1988.

FRASSON, A. P. Z. Caracterização físico-química e biológica e avaliação da atividade antimicrobiana do extrato do caule de Caesalpinia ferrea Mart. Santa Maria, 142 p. Dissertação (Mestrado) - Programa de PósGraduação em Ciência e Tecnologia Farmacêuticas Universidade Federal de Santa Maria, 2002.

GLASL, H. Zur Photometrie in der Drogenstandardisierung - 3. Gehaltsbestimmung von Gerbstoffdrogen. Deutscher Apotheker Zeitung, v. 123, p. 1979, 1983.

HÄNSEL, R.; STICHER, O.; STTEINEGGER, E. Pharmakognosie - Phytopharmazie. 6. Aufl. Berlin : Springer, p. 125-48, 1999.

McPHERSON, D. D.; CORDELL, G. A.; SOEJARTO, D. D., et al. Pentolgynoids and homoisoflavonoids from Caesalpinia pulcherrima. Phytochemistry, v. 22, n. 12, p. 2835-8, 1983.

NAKAMURA, E. S.; KUROSAKI, F.; ARISAWA, M. et al. Cancer chemopreventive effects of constituents of Caesalpinia ferrea and related compounds. Cancer Letters, v. 177, n. 2, p. 119-24, 2002.

NAMIKOSKI, M.; NAKATA, H.; SAITOH, T. Homoisoflavonoids from Caesalpinia sappan. Phytochemistry, v. 26, n. 6, p. 1831-3, 1987.

RATES, S. M. K. Plants as source of drugs. Toxicon, v. 39, p. 603-13, $2001 \mathrm{a}$.

RATES, S. M. K. Promoção do uso racional de fitoterápicos: uma abordagem no ensino de farmacognosia. Revista Brasileira de Farmacognosia, v. 11, n. 2, p. 57-69, 2001 b.

STAHL, E.; JORK, H. Terpene derivatives, essential oils, balsams and resins. IN: STAHL, E. (ed.) Thin-layer cromatography - a laboratory handbook. 2. ed. Berlin: Springer, 1969. p.206-258.

WAGNER, H. Pharmazeutische Biologie. 5.Aufl. Stuttgart: Gustav Fischer, 1993.

WHO. Quality control methods for medicinal plants materials. Geneva: WHO, 1992.

* Autor para correspondência

Profa. Dra. Berta M. Heinzmann

Depto. de Farmácia Industrial - Universidade

Federal de Santa Maria

Prédio 26 - Campus Universitário

97105-900 - Santa Maria, RS

E-mail: hberta@ccs.ufsm.br 